\title{
Dinoflagelados productores de Yessotoxinas en el Mar Argentino
}

\author{
ELENA FABRO ${ }^{1,2 *}$, BERND KROCK³ y GASTÓN O. ALMANDOZ ${ }^{1,2}$
}

\begin{abstract}
Summary: Dinoflagellates producers of yessotoxins in the Argentine Sea. Yessotoxins (YTXs) consist of a recently described group of phycotoxins associated with shellfish toxicity and with cardiotoxicity in laboratory rodents. Until now there are only three dinoflagellate species considered as YTXs producers: Protoceratium reticulatum, Gonyaulax spinifera and Lingulodinium polyedra. In this study the presence of YTX and its potential producers in the Argentine Sea was analyzed by four oceanographic expeditions carried out between 38 and $55^{\circ} \mathrm{S}$ and during different seasons. Toxin detection was performed by application of liquid chromatography coupled to tandem mass spectrometry. Morphological analysis included optical and scanning electron microscopy. Two YTXs potential producers were found: Protoceratium reticulatum and Gonyaulax spinifera, showing highest concentrations of 660 and 140 cell $\mathrm{L}^{-1}$ respectively, during autumn and spring. YTX was also detected during autumn and spring in samples from San Jorge Gulf and slope waters and was associated with the presence of $P$. reticulatum, showing toxin cell quotas of 2.2 and $12.5 \mathrm{pg} \mathrm{YTX} \mathrm{cell}{ }^{-1}$. The data obtained suggest that $P$. reticulatum is the main YTXs producer in the Argentine Sea, while G. spinifera represents a potential producer in the region which did not show a clear association with YTX detection.
\end{abstract}

Key words: Protoceratium reticulatum, Gonyaulax spinifera, yessotoxins, Argentine Sea.

\begin{abstract}
Resumen: Las yessotoxinas (YTXs) son un grupo de ficotoxinas descrito recientemente, asociado a toxicidad en moluscos y a cardiotoxicidad en ratones de laboratorio. Hasta el momento se conocen tres especies de dinoflagelados productoras de YTXs a nivel mundial: Protoceratium reticulatum, Gonyaulax spinifera y Lingulodinium polyedra. En este estudio se analizó la presencia de YTXs y de sus potenciales productores en cuatro campañas oceanográficas realizadas en diferentes estaciones del año entre los 38 y $55^{\circ} \mathrm{S}$. La detección de toxinas se realizó mediante cromatografía líquida de alta eficiencia acoplada con espectrometría de masas en tándem. Los análisis morfológicos incluyeron observaciones mediante microscopía óptica y electrónica de barrido. Se encontraron dos potenciales productores de YTXs, Protoceratium reticulatum y Gonyaulax spinifera, presentando densidades máximas de 660 y 140 cél. $L^{-1}$ respectivamente durante las campañas de otoño y primavera, en las cuales se detectó YTX en muestras del Golfo San Jorge y del talud. Los datos obtenidos sugieren que la especie $P$. reticulatum es la principal productora de YTXs en el Mar Argentino presentando cuotas celulares entre 2,2 y 12,5 pg YTX cél. ${ }^{-1}$, mientras que $G$. spinifera representa un productor potencial en la región que no ha mostrado una asociación clara con la detección de YTX.
\end{abstract}

Palabras clave: Protoceratium reticulatum, Gonyaulax spinifera, yessotoxinas, Mar Argentino.

\section{INTRODUCCIÓN}

Las microalgas planctónicas constituyen un componente biótico esencial presente en todos los mares y océanos del mundo, representan el primer eslabón en la cadena alimentaria y son responsables de la mayor parte de la productividad primaria de los ecosistemas marinos (Graham \& Wilcox, 2000). Los períodos de rápido crecimiento y acumulación de fitoplancton, denominados floraciones, resultan

\footnotetext{
${ }^{1}$ División Ficología, Facultad de Ciencias Naturales y Museo, Universidad Nacional de La Plata. Paseo del Bosque s/n (B1900FWA), La Plata, Argentina.

${ }^{2}$ Consejo Nacional de Investigaciones Científicas y Técnicas (CONICET). Godoy Cruz 2290 (C1425FQB) CABA, Buenos Aires, Argentina.

${ }^{3}$ Alfred Wegener Institut-Helmholtz Zentrum für Polar- und Meeresforschung, Chemische Ökologie, Am Handelshafen 12 , 27570 Bremerhaven, Germany.

*fabroelena@yahoo.com.ar
} 
mayormente beneficiosos para la acuicultura y las pesquerías; sin embargo en algunos casos pueden acarrear efectos negativos tanto para el hombre como para los ecosistemas naturales. A este tipo de proliferaciones dañinas se las conoce como Floraciones Algales Nocivas (FANs) y algunas de ellas son generadas por organismos productores de toxinas que se acumulan a través de las redes tróficas, provocando intoxicaciones en humanos y otros vertebrados principalmente relacionadas con el consumo de moluscos bivalvos.

Las ficotoxinas son un grupo de compuestos químicos de diferente naturaleza y con diversos mecanismos de acción biológica, que pueden provocar distintos síndromes y síntomas en los organismos afectados (Lassus et al., 2016). En particular, las yessotoxinas (YTXs) forman un grupo de aproximadamente 100 análogos de toxinas lipofílicas (Miles et al., 2005) capaces de producir cardiotoxicidad en ratones tras ser inyectadas intraperitonealmente (Terao et al., 1990; Aune et al., 2002) y citotoxicidad frente a algunas líneas celulares de tumores humanos (Konishi et al., 2004). Si bien las YTXs han sido asociadas a toxicidad en moluscos (Satake et al., 1997; MacKenzie et al., 1998) hasta el momento no se han registrado casos de intoxicación de personas, aunque representan un riesgo potencial a la salud humana; por lo cual los países integrantes de la Unión Europea han establecido límites máximos permitidos de YTXs en moluscos para consumo (Gazzetta Ufficiale della Repubblica Italiana, 2002; Munday et al., 2008; Paz et al., 2013).

Los organismos productores de YTXs conocidos hasta el momento pertenecen al grupo de los dinoflagelados, entre ellos Protoceratium reticulatum fue la primera especie en ser considerada como productora de YTXs (Satake et al., 1997). Recientemente, la producción de YTX se confirmó en cultivos de la especie Lingulodinium polyedra mediante espectrometría de masas (LC-MS) (Paz et al., 2004; Armstrong \& Kudela, 2006). Asimismo, L. polyedra fue detectada de manera recurrente formando floraciones en el mar Adriático, durante las cuales también se detectaron YTXs en muestras de plancton (Draisci et al., 1999 como Gonyaulax polyedra; Tubaro et al., 1998 como Lingulodinium polyedrum). Por otro lado, la presencia de G. spinifera en el Mar Adriático en ausencia de $P$. reticulatum y L. polyedra en 2004 y 2006, estuvo asociada al establecimiento de vedas para la recolección de mariscos debido a la detección de YTXs en moluscos recolectados
(Riccardi et al., 2009). Luego, la producción de YTXs por parte de G. spinifera fue confirmada en un cultivo de Nueva Zelanda por medio del método de ELISA (Rhodes et al., 2006) y en dos cultivos obtenidos del Mar Adriático utilizando LC-MS (Riccardi et al., 2009).

Protoceratium reticulatum es una especie de amplia distribución en mares y océanos de Europa, América, África, Asia y Oceanía (Lassus et al., 2016). Particularmente en Argentina, P. reticulatum ha sido recientemente asociada a la presencia de YTXs en muestras de plancton del Golfo San Jorge, a partir de las cuales se estableció un cultivo que mostró un perfil de toxinas dominado por YTX $(>95 \%)$, con la detección de otros cuatro derivados en forma minoritaria, los cuales no pudieron determinarse fehacientemente a causa de la falta de material de referencia (Akselman et al., 2015). Por otro lado, $G$. spinifera es una especie cosmopolita y ampliamente distribuida en el Mar Argentino (Balech, 1988; Akselman, 1996), la cual no parece contribuir significativamente a la producción de YTXs en el Golfo San Jorge (Akselman et al., 2015). A pesar de que no existen registros de células vegetativas de L. polyedra en el plancton del Mar Argentino, se han encontrado sus quistes en sedimentos correspondientes a una estación fija (EPEA) ubicada en las cercanías de Mar del Plata y en la zona común de pesca entre Argentina y Uruguay (Akselman et al., 2015).

En el presente trabajo se describen la distribución y abundancia de las especies previamente citadas como productoras de YTXs junto con la detección y concentración de YTXs en el Mar Argentino en 121 muestras de plancton colectadas a lo largo de cuatro expediciones oceanográficas llevadas a cabo en diferentes estaciones del año.

\section{Materiales y Métodos}

\section{Recolección de muestras}

El área de estudio abarcó un extenso sector de la plataforma continental y el talud del Mar Argentino entre los 38 y $56^{\circ} \mathrm{S}$, muestreado durante cuatro campañas oceanográficas llevadas a cabo en distintas estaciones del año (primavera, verano y otoño) entre los años 2012 y 2016, con un total de 121 puntos de muestreo (Fig. 1).

La primera campaña, de aquí en adelante denominada "campaña de otoño" o "C1", tuvo 


\section{E. Fabro et al. - Dinoflagelados productores de yessotoxinas en el Mar Argentino}

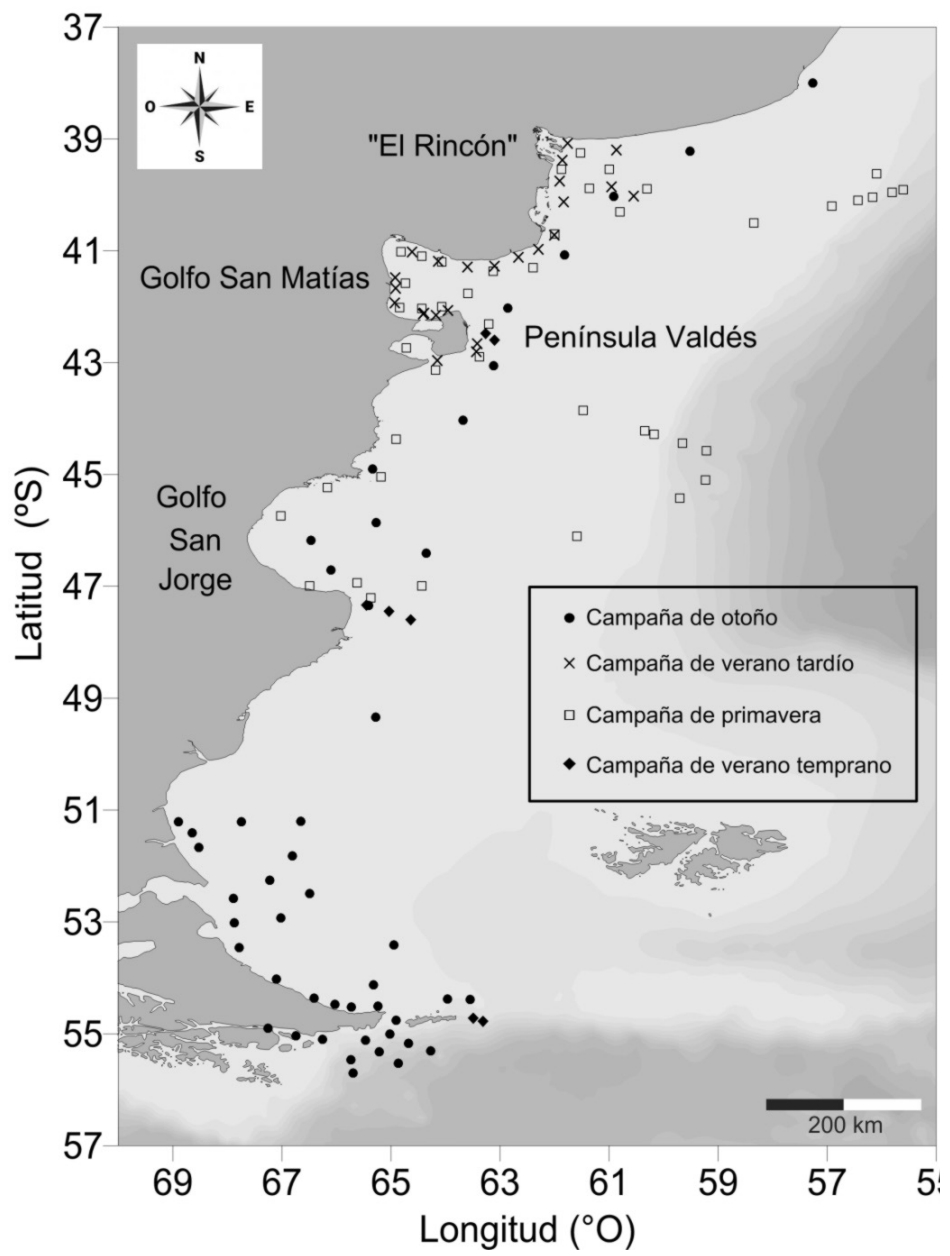

Fig. 1. Mapa del área de estudio indicando los puntos de muestreo de las cuatro campañas oceanográficas realizadas.

lugar a bordo del buque oceanográfico R/V "Puerto Deseado" desde el 30 de marzo hasta el 14 de abril del año 2012, con un total de 46 estaciones de muestreo entre los 38 y los $56^{\circ} \mathrm{S}$. La segunda campaña, de aquí en adelante denominada "campaña de verano tardío" o "C2", se realizó del 11 al 22 de marzo del año 2013 a bordo del buque oceanográfico R/V "Bernardo Houssay" y constó de 24 estaciones de muestreo entre los 39 y los $43^{\circ} \mathrm{S}$. Estuvo dividida en dos piernas: la $\mathrm{K} 1$ con 8 estaciones desde los 39 hasta los $40.7^{\circ} \mathrm{S}$, y la K2 con 16 estaciones desde los 41 a los $43^{\circ} \mathrm{S}$. La tercera campaña, denominada en adelante "campaña de primavera" o "C3", se llevó a cabo desde el 26 de octubre al 9 de noviembre del año 2013 a bordo del buque oceanográfico R/V "Puerto Deseado" con 44 estaciones de muestreo localizadas entre los 39 y los $47^{\circ} \mathrm{S}$. La cuarta y última campaña, llamada en adelante "campaña de verano temprano" o "C4", se llevó a cabo desde el 6 al 12 de enero de 2016 a bordo del buque oceanográfico "Bernardo Houssay" y constó de un total de 7 puntos de muestreo, dos de ellos localizados frente a Península Valdés, tres al sur del Golfo San Jorge y los otros dos frente a la Isla de los Estados (Tierra del Fuego).

En cada una de las campañas oceanográficas y para cada estación de muestreo se tomaron muestras cuantitativas y cualitativas para el análisis del fitoplancton en forma simultánea con la toma de muestras destinadas al estudio de las ficotoxinas. En todas las estaciones de muestreo se obtuvieron datos de salinidad, temperatura y profundidad 
(CTD), excepto en las ubicadas en la pierna $\mathrm{K} 2$ de la $\mathrm{C} 2$, en la cual únicamente se midió la temperatura superficial con un sensor multiparamétrico TOADKK Modelo WQC.

Para la toma de muestras cuantitativas se utilizó una roseta equipada con sensores de temperatura y salinidad y botellas Niskin de 5 litros. Las botellas se llenaron con agua de superficie (entre 3 y 10 metros) y $250 \mathrm{~mL}$ se fijaron con lugol acético (concentración final $=2 \%$ ) para los análisis microscópicos de la comunidad planctónica y se mantuvieron en oscuridad y a temperatura ambiente hasta el momento de su análisis.

Las muestras cualitativas se colectaron mediante arrastres verticales desde los 20 metros de profundidad hasta la superficie, utilizando una red de $20 \mu \mathrm{m}$ de malla y 30 centímetros de diámetro. Cada lance de red se llevó a un volumen total de 1 $\mathrm{L}$ agregando agua de mar filtrada con filtro de $5 \mu \mathrm{m}$ de malla a fin de estandarizar el volumen total de muestra y de esa manera poder tomar alícuotas para los análisis morfológicos y toxinológicos de igual volumen en todas las estaciones de muestreo. Para el estudio morfológico e identificación de las distintas especies, fueron obtenidas alícuotas de $20 \mathrm{~mL}$ (C1) y $100 \mathrm{~mL}$ (C2-C4) que se fijaron con lugol acético (concentración final $=2 \%$ ) y se mantuvieron en la oscuridad y a temperatura ambiente hasta el momento de su análisis. La cantidad restante de muestra se filtró por gravedad a través de un tamiz compuesto de tres mallas de Nitex de 200, 50 y $20 \mu \mathrm{m}$. Luego el material colectado en cada malla fue resuspendido hasta un volumen final de $40 \mathrm{~mL}$ utilizando agua de mar filtrada y una piseta. El material obtenido de cada fracción de tamaño fue centrifugado en tubos de centrifugación de $45 \mathrm{~mL}$ durante 30 minutos a $3.000 \mathrm{x} \mathrm{g}$. Los pellets resultantes de esta primera centrifugación fueron divididos en dos alícuotas iguales, destinadas al análisis de toxinas lipo- e hidrofílicas. Una vez realizada la división en alícuotas, las muestras fueron centrifugadas nuevamente en tubos de $2 \mathrm{~mL}$ durante 15 minutos a $10.000 \mathrm{x}$ g. Los pellets obtenidos de la segunda centrifugación fueron guardados a $-4{ }^{\circ} \mathrm{C}$ para la extracción de toxinas. Durante la $\mathrm{C} 1$ no se obtuvieron muestras de red en las estaciones I12 e I13 debido a problemas meteorológicos.

\section{Análisis microscópicos}

El análisis de las muestras cuantitativas se realizó mediante la técnica de Utermöhl (1958) utilizando un microscopio invertido con contraste de fases Leica
DMIL LED. Se dejaron sedimentar $50 \mathrm{~mL}$ de muestra de cada estación de muestreo durante 24 horas. Para la cuantificación de los organismos se examinó la superficie total de la cámara de sedimentación o una cantidad variable de campos al azar $(\geq 10)$, dependiendo de la cantidad de organismos presentes de los diferentes taxones. El límite de detección fue de 20 cél. $\mathrm{L}^{-1}$.

Adicionalmente se realizaron análisis cualitativos de las muestras de red con el objetivo de determinar los dinoflagelados toxígenos hasta el menor nivel taxonómico posible. A tal fin se realizaron observaciones de alícuotas de muestra de cada estación mediante un microscopio de contraste de fase equipado con una lámpara de epifluorescencia y uno de contraste de interferencia modelo Leica DM2500, ambos equipados con una cámara DFC420C. Para el estudio taxonómico detallado de los dinoflagelados se observaron alícuotas teñidas con CalcoFluor utilizando microscopía de epifluorescencia UV, de acuerdo a Fritz \& Triemer (1985). Los análisis ultraestructurales se realizaron utilizando un microscopio electrónico de barrido Jeol JSM-6360 LV del Servicio de Microscopía Electrónica de Barrido (MEB) del Museo de La Plata y un microscopio electrónico de barrido Carl Zeiss NTS (SUPRA 40) del Centro de Microscopías Avanzadas (CMA) de la Universidad de Buenos Aires. El material a analizar se deshidrató a través de series de diluciones de etanol $(25,50,75,100 \%)$ y el secado final se realizó utilizando la técnica de punto crítico. Por último las muestras se metalizaron con oro previo a su observación al MEB.

Finalmente, con el propósito de analizar la relación entre la densidad celular de dinoflagelados potencialmente productores de YTXs y la concentración de las mismas, se realizaron recuentos celulares de alícuotas de $1 \mathrm{~mL}$ de las muestras de red utilizando cámaras Sedgewick-Rafter (LeGresley $\&$ McDermott, 2010) en un microscopio invertido con contraste de fases Leica DMIL LED. Para la cuantificación de los organismos se examinó la superficie total de la cámara utilizando un aumento de $10 \mathrm{X}$, o una cantidad variable de campos al azar $(\geq 10)$ utilizando un aumento de $20 \mathrm{X}$, dependiendo de la cantidad de organismos presentes. Las densidades estimadas se expresan como células por lance de red (cél. LR ${ }^{-1}$ ).

El grado de asociación entre células y toxinas se estableció mediante el índice de correlación de Spearman aplicando el software Statistica 7.1. 


\section{E. Fabro et al. - Dinoflagelados productores de yessotoxinas en el Mar Argentino}

\section{Análisis de toxinas}

Para el análisis de toxinas lipofílicas los pellets obtenidos de las muestras de red se resuspendieron en $500 \mu \mathrm{L}$ de metanol y homogeneizaron junto con $0,9 \mathrm{~g}$ de matriz lítica $\mathrm{D}$ (esferas pequeñas utilizadas para la ruptura de paredes celulares) utilizando un homogeneizador por batido Bio101 FastPrep a $6,5 \mathrm{~m} \mathrm{~s}^{-1}$ por $45 \mathrm{~s}$. Luego de la homogenización, las muestras fueron centrifugadas a $16.100 \mathrm{x}$ g a $4^{\circ} \mathrm{C}$ por $15 \mathrm{~min}$. Los sobrenadantes fueron transferidos a filtros de centrifugación de $0,45 \mu \mathrm{m}$ de poro (Millipore Ultrafree, Eschborn, Alemania) y centrifugados durante $30 \mathrm{~s} \mathrm{a} 800 \mathrm{x}$ g. Por último, los filtrados se transfirieron a viales para su análisis con cromatografía líquida (HPLC) acoplada con espectrometría de masa en tándem (MS-MS) en la División de Química Ecológica del Alfred Wegener Institute, Bremerhaven, Alemania, como se describe en Krock et al. (2008). Los datos se presentan como nanogramos detectados por lance de red $\left(n g \mathrm{LR}^{-1}\right)$.

\section{Estimación de cuotas celulares}

Con el propósito de estimar las cuotas celulares de YTX, entendidas como la cantidad promedio de toxina presente en una célula, se utilizaron los resultados de los recuentos celulares y los de análisis de toxinas, realizados a partir de muestras de red. A tal fin se realizó el cociente entre el contenido de toxinas y el número de células para cada estación de muestreo. Sólo se estimaron cuotas celulares de toxinas en las estaciones de muestreo en las cuales se encontró una única especie potencialmente productora de la toxina en cuestión o, en el caso de haber más de un productor potencial, las cuotas se calcularon sólo cuando una de las especies representó al menos el 90\% del total de células de los productores potenciales.

De acuerdo a las recomendaciones reportadas por el Consejo Internacional para la Exploración del Mar (en inglés: International Council for the Exploration of the Sea, ICES) (ICES, 2006), sólo se estimaron cuotas celulares para aquellas muestras en las que se contaron más de 10.000 células por litro de muestra de red del taxón toxígeno a considerar en las cuotas celulares.

Las toxinas presentes en la fracción $>200 \mu \mathrm{m}$ no fueron consideradas en la estimación de cuotas celulares ya que no existen productores de YTXs mayores a $200 \mu \mathrm{m}$. Las cuotas celulares de toxinas se expresan como picogramos de toxina por célula (pg cél. ${ }^{-1}$ ).

\section{Resultados}

Descripción morfológica de las especies encontradas

Protoceratium reticulatum (Claparède \& Lachmann) Bütschli (Fig. 2)

Balech (1988): 169, Lam. 77, Figs. 1-5 (Gonyaulax grindleyi)

Basiónimo: Peridinium reticulatum Claparède \& Lachmann.

Sinónimos: Peridiniopsis reticulatum (Claparède \& Lachmann) Starmach; Gonyaulax grindleyi Reinecke.

Contorno ovoide, pentagonal a poligonal, sin cuello ni espinas. Epiteca con forma de domo, más pequeña que la hipoteca (Figs. 2 A, B). Reticulación tecal muy particular formada por un reticulado de areolas poligonales, cada una con una protuberancia central en forma de cresta, la cual posee un poro (Figs. 2 B, C). Cingulum muy excavado, con marcada reticulación, descendente (1-1,5 veces su altura) y sin entrecruzamiento; sulcus angosto y corto (Figs. 2 C, D). Placa 1' con un poro en la región apical derecha (Figs. $2 \mathrm{C}, \mathrm{D})$. Presencia de tres placas apicales (3') y una placa intercalar (1a) en todas las células analizadas $(n=20)$ (Figs. 2 E-H).

Dimensiones: largo 39-55,5 $\mu \mathrm{m}$ (promedio 46 $\mu \mathrm{m}, \pm 4$ ); ancho 33-48 $\mu \mathrm{m}$ (promedio $40 \mu \mathrm{m}, \pm 4$ ) $(n=23)$.

Gonyaulax spinifera (complejo de especies) (Claparède \& Lachmann) Diesing (Fig. 3)

Balech (1988): 166, Lam. 74, Figs. 1-4.

Basiónimo: Peridinium spiniferum Claparède \& Lachmann

Sinónimos: Peridinium levanderi Lemmermann; Spiniferites ramosus (Ehrenberg) Mantell; Gonyaulax levanderi (Lemmermann) Paulsen; Tectatodinium pellitum Wall.

Contorno celular caracterizado por la presencia de espinas antapicales bien desarrolladas (Fig. 3 A), un cuello prominente y hombro derecho muy marcado (Figs. 3 A, B). Cingulum muy excavado y claramente descendente (2-2,5 veces su altura) con entrecruzamiento muy evidente (Figs. 3 C-E). Placa 6" triangular con un borde izquierdo cóncavo (Figs. $3 \mathrm{C}, \mathrm{D})$. Areolas casi circulares las cuales pueden o no estar perforadas o presentar poros entre ellas (Figs. 3 D-F). Presencia de dos (Figs. 3 D, E) o tres (Fig. 3 F) espinas antapicales. 

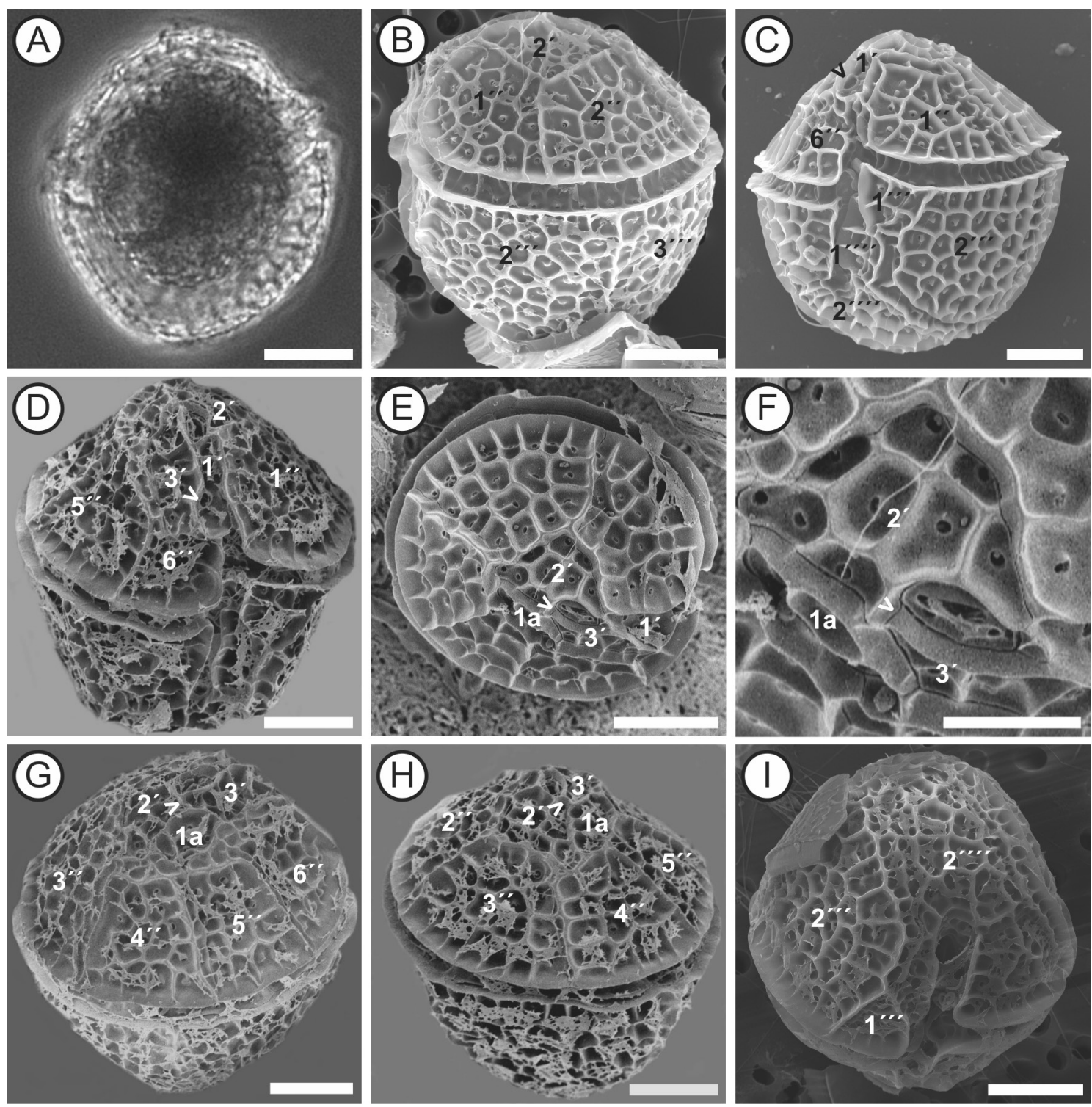

Fig. 2. Protoceratium reticulatum. (A) Microscopía óptica con contraste de fases, (B-I) Microscopía electrónica de barrido. A, B: Vista general lateral. C, D: Vista ventral, note la presencia de un poro ventral en la placa 1' (flechas). E: Vista apical, note la presencia de la placa intercalar (1a). F: Detalle de E, note la sutura entre las placas 2' y 3' (flecha). G, H: Vista dorso-apical, note la sutura entre las placas 2' y 3' (flechas). I: Vista antapical. Escala= A-E, G-I: $10 \mu \mathrm{m}$. Escala= F: $5 \mu \mathrm{m}$.

Dimensiones: largo 37-69 $\mu \mathrm{m}$ (promedio $51 \mu \mathrm{m}, \pm$ 9); ancho 32-55 $\mu \mathrm{m}$ (promedio $43 \mu \mathrm{m}, \pm 7)$; $(n=20)$.

Distribución, abundancia y toxinas asociadas Campaña de otoño (C1)

La especie Protoceratium reticulatum estuvo presente en cuatro muestras cuantitativas colectadas en el Golfo San Jorge y aguas circundantes (Fig. 4 A) en abundancias de 20 a 120 cél. $\mathrm{L}^{-1}$ que representaron entre el 0,1 y $1,3 \%$ de la abundancia total de los dinoflagelados (promedio $=0,5 \%$ ). Adicionalmente se la encontró en una muestra de red colectada en aguas adyacentes a la boca del Golfo San Jorge $\left(45^{\circ} \mathrm{S}\right)$. Por su parte, se detectaron representantes del complejo Gonyaulax spinifera 


\section{E. Fabro et al. - Dinoflagelados productores de yessotoxinas en el Mar Argentino}
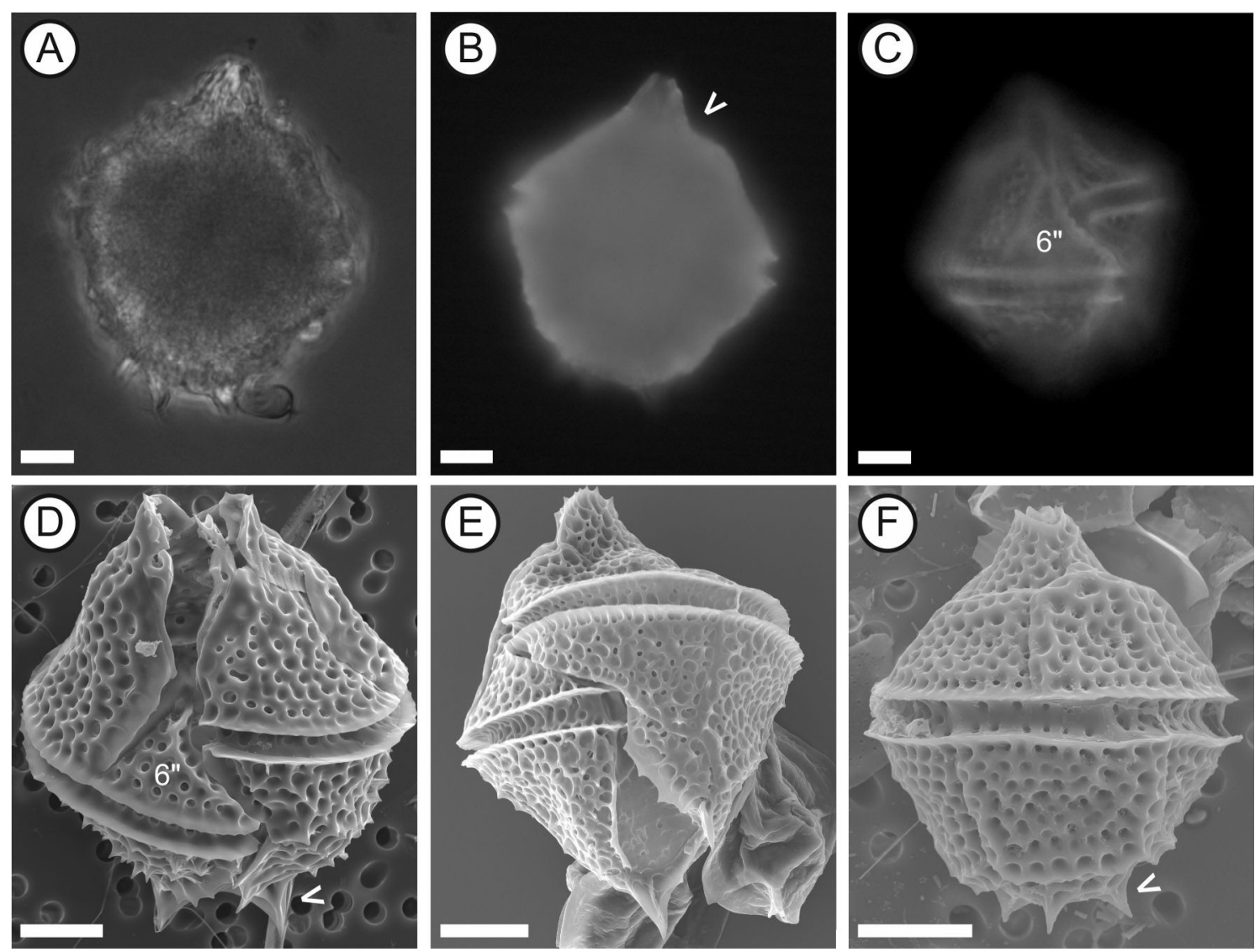

Fig. 3. Gonyaulax spinifera. (A) Microscopía óptica, (B, C) Microscopía óptica de fluorescencia y (D-F) Microscopía electrónica de barrido. A, B: Vista general dorsal, note las espinas antapicales, el prominente cuello y el hombro derecho marcado (flecha). C: Vista ventro-lateral derecha, note la forma triangular de la placa 6" y el marcado desplazamiento descendente del cingulum. D: Vista ventro-apical, note el borde izquierdo cóncavo de la placa 6" y la presencia de dos espinas antapicales (flecha). E: Vista ventral, note el entrecruzamiento cingular. F: Vista dorsal, note la presencia de tres espinas antapicales (flecha). Escala= $10 \mu \mathrm{m}$.

en tres muestras cuantitativas correspondientes al Golfo San Jorge y aguas circundantes, en las que representaron entre el 0,5 y $1,5 \%$ de la abundancia total de los dinoflagelados (promedio $=0,8 \%$ ). El complejo G. spinifera se encontró además en tres muestras de red correspondientes a dos estaciones ubicadas en el Golfo San Jorge y a una al norte del golfo $\left(44^{\circ} \mathrm{S}\right)$ (Fig. $\left.4 \mathrm{~B}\right)$.

El rango de temperatura en que se encontraron células de $P$. reticulatum fue de 12 a $14{ }^{\circ} \mathrm{C}$ y el de salinidad de 33,3 a 33,6. G. spinifera se encontró en un rango de temperatura de 12 a $16{ }^{\circ} \mathrm{C}$ y a salinidades de 33,4 a 33,9. Las densidades celulares máximas de ambas especies se presentaron a $13{ }^{\circ} \mathrm{C}$ y 33,4 de salinidad.
La presencia de YTX se detectó en cinco estaciones correspondientes al Golfo San Jorge, en muestras de la fracción de 20 a $50 \mu \mathrm{m}$ en concentraciones de 24 a $343 \mathrm{ng} \mathrm{LR}^{-1}$ (Tabla 1). Adicionalmente se detectó YTX en tres muestras de la fracción de 50-200 $\mu \mathrm{m}$ correspondientes a estaciones de la misma zona.

En las cinco estaciones con detección de YTX (Fig. 5) también se encontraron células de $P$. reticulatum en muestras de red no fraccionadas, en abundancias entre 4 y 40 × $10^{3}$ cél. LR $^{-1}$; presentando una correlación alta y significativa entre densidad celular y concentración de toxinas $(r=0,99 \mathrm{p}<$ $0,05)$. Por otro lado, en cuatro de ellas también se encontraron células de G. spinifera, aunque siempre 

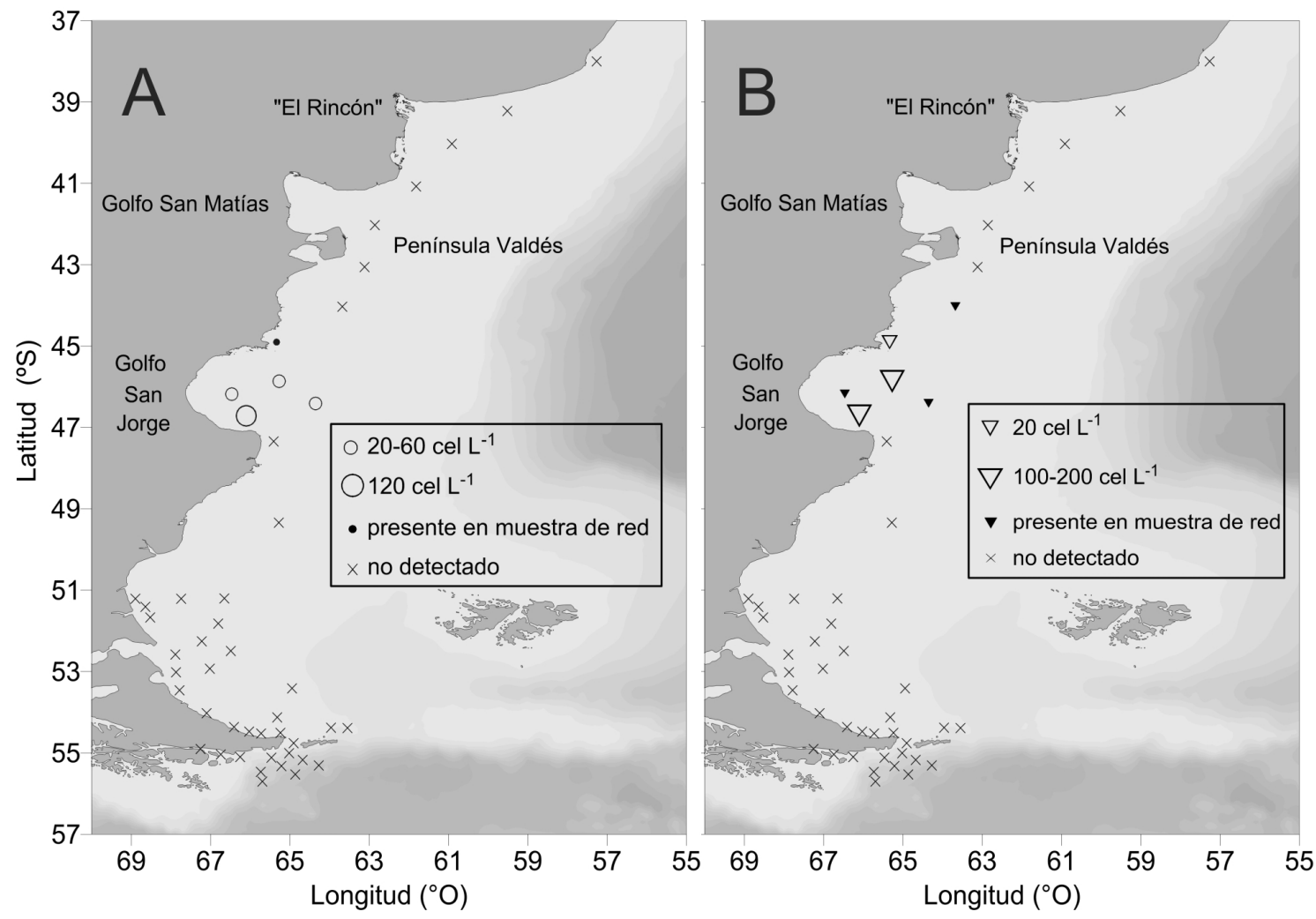

Fig. 4. Distribución y abundancia en muestras cuantitativas y presencia en muestras cualitativas de Protoceratium reticulatum (A) y Gonyaulax spinifera (B) durante la C1.

en menor abundancia que $P$. reticulatum (Fig. 5) y presentando una menor correlación $(\mathrm{r}=0,87 \mathrm{p}<$ $0,05)$. Las cuotas celulares de YTX estimadas para $P$. reticulatum, en las dos estaciones con densidades suficientes, fueron de 7,5 y 12,5 pg cél. ${ }^{-1}$.

\section{Campaña de verano tardio (C2)}

Protoceratium reticulatum no se detectó ni en las muestras cuantitativas ni en las cualitativas durante esta campaña. Por el contrario, el complejo de especies $G$. spinifera se encontró en nueve muestras cualitativas correspondientes al Golfo San Matías (Fig. 6), en abundancias de 3 a $28 \times 10^{3}$ cél. LR $^{-1}$, pero no se detectó en ninguna muestra cuantitativa. El rango de temperatura en que se encontraron células de G. spinifera fue de 14 a $18{ }^{\circ} \mathrm{C}$. No se detectaron YTXs durante esta campaña (Tabla 1).

\section{Campaña de primavera (C3)}

La especie $P$. reticulatum estuvo presente en tres muestras cuantitativas ubicadas al norte del Golfo
San Jorge y en aguas de plataforma cercanas al talud a los $44^{\circ} \mathrm{S}$ en abundancias de 20 a 660 cél. L ${ }^{-1}$ y representó entre el 0,1 y $4,5 \%$ de la abundancia total de los dinoflagelados (promedio $=1,6 \%$ ). Adicionalmente, se la encontró en cinco muestras cualitativas correspondientes al Golfo San Jorge y a aguas del talud a los $39 \mathrm{y} 44^{\circ} \mathrm{S}$ (Fig. 7 A).

En seis muestras cuantitativas correspondientes al Golfo San Jorge y aguas del talud a los 39 y $44^{\circ} \mathrm{S}$ se detectaron representantes del complejo G. spinifera. Las densidades celulares alcanzadas variaron entre 20 y 140 cél. $\mathrm{L}^{-1}$ y representaron entre el 0,03 y $1,3 \%$ de la abundancia total de los dinoflagelados (promedio $=0,3 \%$ ). Además se encontraron células del complejo en 11 muestras cualitativas obtenidas en aguas del talud, en el Golfo San Jorge y en aguas adyacentes a la Península Valdés (Fig. 7 B).

El rango de temperatura en que se encontraron células de $P$. reticulatum fue de 10 a $12{ }^{\circ} \mathrm{C}$ y la salinidad de 33,1 a 33,7, con densidades celulares 


\section{E. Fabro et al. - Dinoflagelados productores de yessotoxinas en el Mar Argentino}

Tabla 1. Tabla resumen de los resultados de abundancias de $P$. reticulatum, G. spinifera y YTX, cuotas celulares y correlaciones a lo largo de las cuatro campañas realizadas. $n d=$ no detectado, $n=$ cantidad de muestras, - = sin datos.

\begin{tabular}{|c|c|c|c|c|}
\hline & $\mathrm{C} 1$ & C2 & C3 & $\mathrm{C} 4$ \\
\hline \multicolumn{5}{|l|}{$\begin{array}{l}\text { Abundancia en } \\
\text { muestras de botella } \\
\text { (cuantitativas) }\end{array}$} \\
\hline P. reticulatum & 20-120 cél. L-1 $(n=4)$ & nd & 20-660 cél. L-1 $(n=3)$ & nd \\
\hline G. spinifera & 20-140 cél. $L^{-1}(n=3)$ & nd & $20-140$ cél. $L^{-1}(n=6)$ & nd \\
\hline \multicolumn{5}{|l|}{$\begin{array}{l}\text { Abundancia en } \\
\text { muestras de red } \\
\text { fracción } 20-50 \mu \mathrm{m}\end{array}$} \\
\hline P. reticulatum & - & - & $1-126 \times 10^{3}$ cél. $(n=8)$ & - \\
\hline G. spinifera & - & - & $1-21 \times 10^{3}$ cél. $(n=17)$ & - \\
\hline YTX & $24-343(n=5)$ & nd & $14-283$ ng LR $\operatorname{LR}^{-1}(n=4)$ & nd \\
\hline \multicolumn{5}{|l|}{$\begin{array}{l}\text { Abundancia en } \\
\text { muestras de red } \\
\text { fracción } 50-200 \mu \mathrm{m}\end{array}$} \\
\hline P. reticulatum & - & - & $1-13$ x $10^{3}$ cél. $(n=7)$ & - \\
\hline G. spinifera & - & - & 1-15x 10³ cél. $(n=16)$ & - \\
\hline YTX & $68-160$ ng LR ${ }^{-1}(n=3)$ & nd & $88 n g \operatorname{LR}^{-1}(n=1)$ & nd \\
\hline \multicolumn{5}{|l|}{$\begin{array}{l}\text { Abundancia en } \\
\text { muestras de red } \\
\text { fracciones integradas }\end{array}$} \\
\hline P. reticulatum & 4-40 x $10^{3}$ cél. LR ${ }^{-1}(n=5)$ & nd & $1-139 \times 10^{3}$ cél. LR ${ }^{-1}(n=8)$ & nd \\
\hline G. spinifera & 2-20 x $10^{3}$ cél. LR ${ }^{-1}(n=6)$ & 3-28 x $10^{3}$ cél. LR ${ }^{-1}(\mathrm{n}=9)$ & 1-36 x 10³ cél. LR ${ }^{-1}(n=17)$ & $9-12 \times 10^{3}$ cél. LR ${ }^{-1}(n=2)$ \\
\hline YTX & $24-343 n g L^{-1}(n=5)$ & nd & $14-371 \mathrm{ng} \mathrm{LR}^{-1}(\mathrm{n}=4)$ & nd \\
\hline \multicolumn{5}{|l|}{ Cuotas celulares } \\
\hline $\begin{array}{l}\text { P. reticulatum } \\
\text { (fracción } 20-50 \mu \mathrm{m} \text { ) }\end{array}$ & - & - & 2,2 ng cél. ${ }^{-1}$ & - \\
\hline $\begin{array}{l}\text { P. reticulatum } \\
\text { (fracción } 50-200 \mu \mathrm{m} \text { ) }\end{array}$ & - & - & 6,5 ng cél. ${ }^{-1}$ & - \\
\hline $\begin{array}{l}P \text {. reticulatum } \\
\text { (fracciones integradas) }\end{array}$ & 7,5-12,5 ng cél..$^{-1}(n=2)$ & nd & 3 ng cél. ${ }^{-1}$ & nd \\
\hline \multicolumn{5}{|l|}{ Correlación } \\
\hline P. reticulatum y YTX & $r=0,99$ & nd & $r=0,73 / 0,4$ & nd \\
\hline G. spinifera y YTX & $r=0,87$ & nd & $r=0,17$ & nd \\
\hline
\end{tabular}

máximas a $12{ }^{\circ} \mathrm{C}$ y 33,4 . G. spinifera se encontró a temperaturas entre 7 y $12{ }^{\circ} \mathrm{C}$ y a salinidades entre 33,4 y 33,9 , con densidades celulares máximas a 8 ${ }^{\circ} \mathrm{C}$ y a una salinidad de 33,9 .

La presencia de YTX se detectó en cuatro estaciones, para la fracción del fitoplancton de 20$50 \mu \mathrm{m}$, en aguas del talud y de la plataforma a los $44^{\circ} \mathrm{S}$ y del Golfo San Jorge. Las concentraciones halladas variaron entre 14 y $283 \mathrm{ng} \mathrm{LR}^{-1}$ (Tabla 1).
Además se detectó YTX en la fracción de 50-200 $\mu \mathrm{m}$ de la estación 45 , correspondiente a aguas de plataforma cercanas al talud a los $44^{\circ} \mathrm{S}$, en una concentración de $88 \mathrm{ng} \mathrm{LR}^{-1}$. P. reticulatum estuvo presente en todas las muestras en las que se detectó YTX (Fig. 8), tanto en las cuatro correspondientes a la fracción de 20-50 $\mu \mathrm{m}$ como en la de la fracción de 50-200 $\mu \mathrm{m}$. Adicionalmente la especie fue hallada en concentraciones bajas $\left(<2 \times 10^{3}\right.$ cél. $\left.\mathrm{LR}^{-1}\right)$ en 

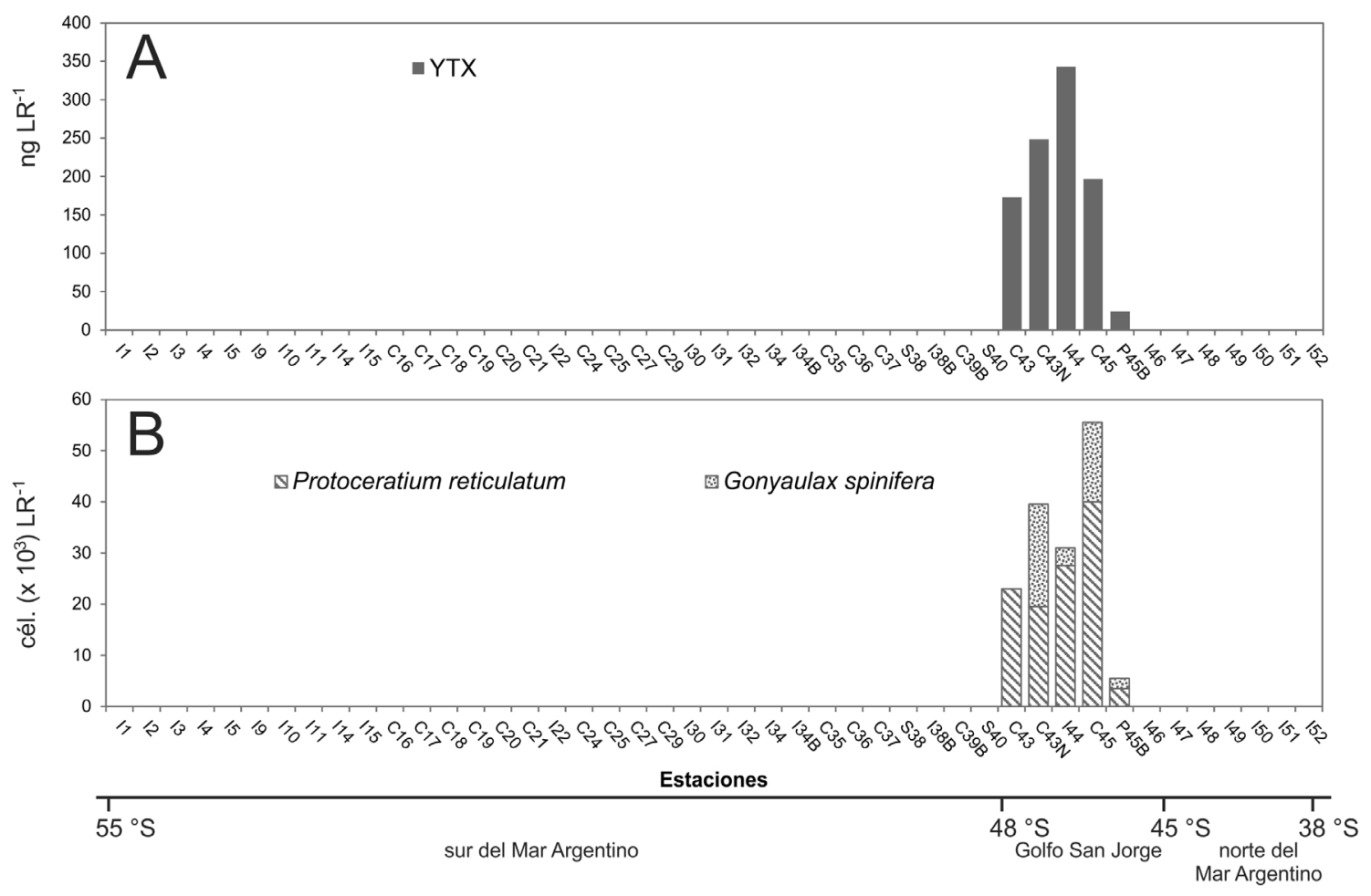

Fig. 5. Concentración de YTX (A) en la fracción de 20-50 $\mu$ m y abundancia de células de $P$. reticulatum y $G$. spinifera (B) en muestras cualitativas no fraccionadas a lo largo de la C1.

cuatro muestras de la fracción menor y en seis de la fracción mayor en las cuales no se detectaron YTXs.

Los valores de abundancia celular de $P$. reticulatum y concentración de YTX presentaron una correlación significativa en ambas fracciones $(\mathrm{r}=0,73$ y $0,4 \mathrm{p}<0,05)$. Las cuotas celulares de YTX estimadas para $P$. reticulatum en la fracción de 20-50 $\mu \mathrm{m}$ y de $50-200 \mu \mathrm{m}$ fueron de 2,2 y $6,5 \mathrm{pg}$ cél. ${ }^{-1}$ respectivamente.

En tres de las cuatro muestras en las que se detectaron toxinas en la fracción de 20-50 $\mu \mathrm{m}$ se encontraron células correspondientes al complejo $G$. spinifera, aunque siempre en abundancias inferiores a $P$. reticulatum. La correlación entre densidad celular de G. spinifera y YTX resultó baja y no significativa $(r=0,17 \mathrm{p}>0,05)$.

\section{Campaña de verano temprano (C4)}

Protoceratium reticulatum no se detectó en muestras cuantitativas ni cualitativas, mientras que el complejo G. spinifera se observó en dos muestras de red correspondientes al sur del Mar Argentino $\left(55^{\circ} \mathrm{S}\right)$, en densidades de 9 y 12 x $10^{3}$ cél. LR ${ }^{-1}$ (Fig. 9). El rango de temperatura en que se encontraron células del complejo G. spinifera fue de 5 a $8{ }^{\circ} \mathrm{C}$ y la salinidad de 33,5 a 34 . No se detectaron YTXs durante esta campaña (Tabla 1).

\section{Discusión}

Variabilidad morfológica de los taxones identificados

Si bien $P$. reticulatum y $G$. spinifera pertenecen a géneros diferentes, son morfológicamente semejantes entre sí, con una estructura fina muy similar y semejanzas a nivel ultraestructural de las organelas (plástidos, pirenoide y sistema pusular) (Hansen et al., 1996/1997). Sin embargo, la diferenciación morfológica puede realizarse mediante microscopía óptica en base a caracteres de la forma general de la célula, la posición del cingulum, la reticulación tecal y la presencia/ ausencia de espinas antapicales (Balech, 1988). 


\section{E. Fabro et al. - Dinoflagelados productores de yessotoxinas en el Mar Argentino}

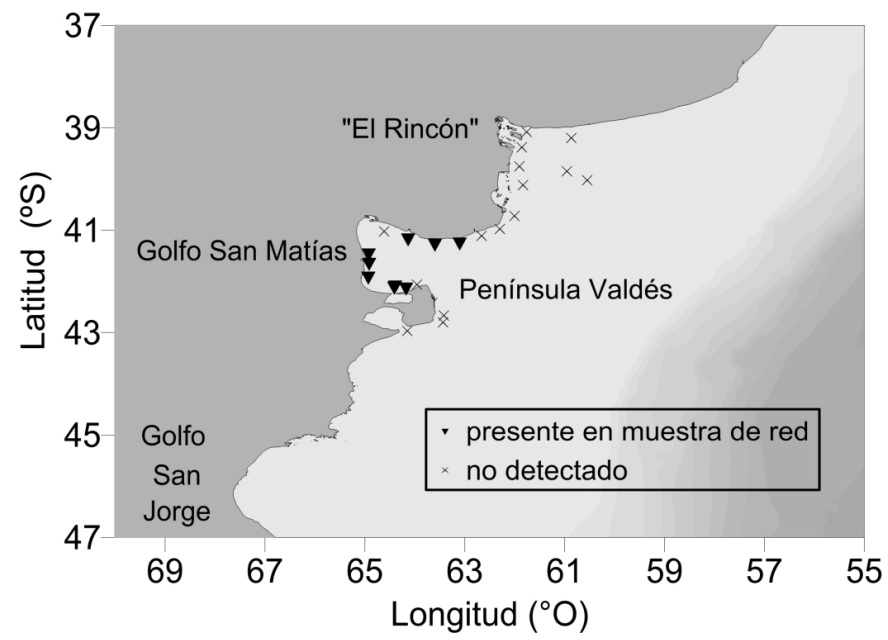

Fig. 6. Distribución del complejo Gonyaulax spinifera en muestras de red durante la C2.

Los ejemplares de $P$. reticulatum analizados en este estudio son morfológicamente semejantes a los descriptos por Balech (1988 bajo el nombre Gonyaulax grindleyi), aunque presentan diferencias en el rango de tamaño de las células (largo: 39,055,5 $\mu \mathrm{m}$; ancho: 33-48 $\mu \mathrm{m}$ ) el cual fue levemente mayor al descripto por Balech (1988) para especímenes del Mar Argentino (largo: 35-45 $\mu \mathrm{m}$, ancho: 28-37 $\mu \mathrm{m}$ ) y por Akselman et al. (2015) para el Golfo San Jorge (largo: 34-39 $\mu \mathrm{m}$, ancho: 29-31 $\mu \mathrm{m})$. En este sentido, Paz et al. (2013) encontraron una variación significativa en el biovolumen de distintas cepas de $P$. reticulatum aisladas de aguas marinas de España. Los especímenes analizados durante este estudio presentaron en la epiteca tres placas apicales y una intercalar, lo cual concuerda
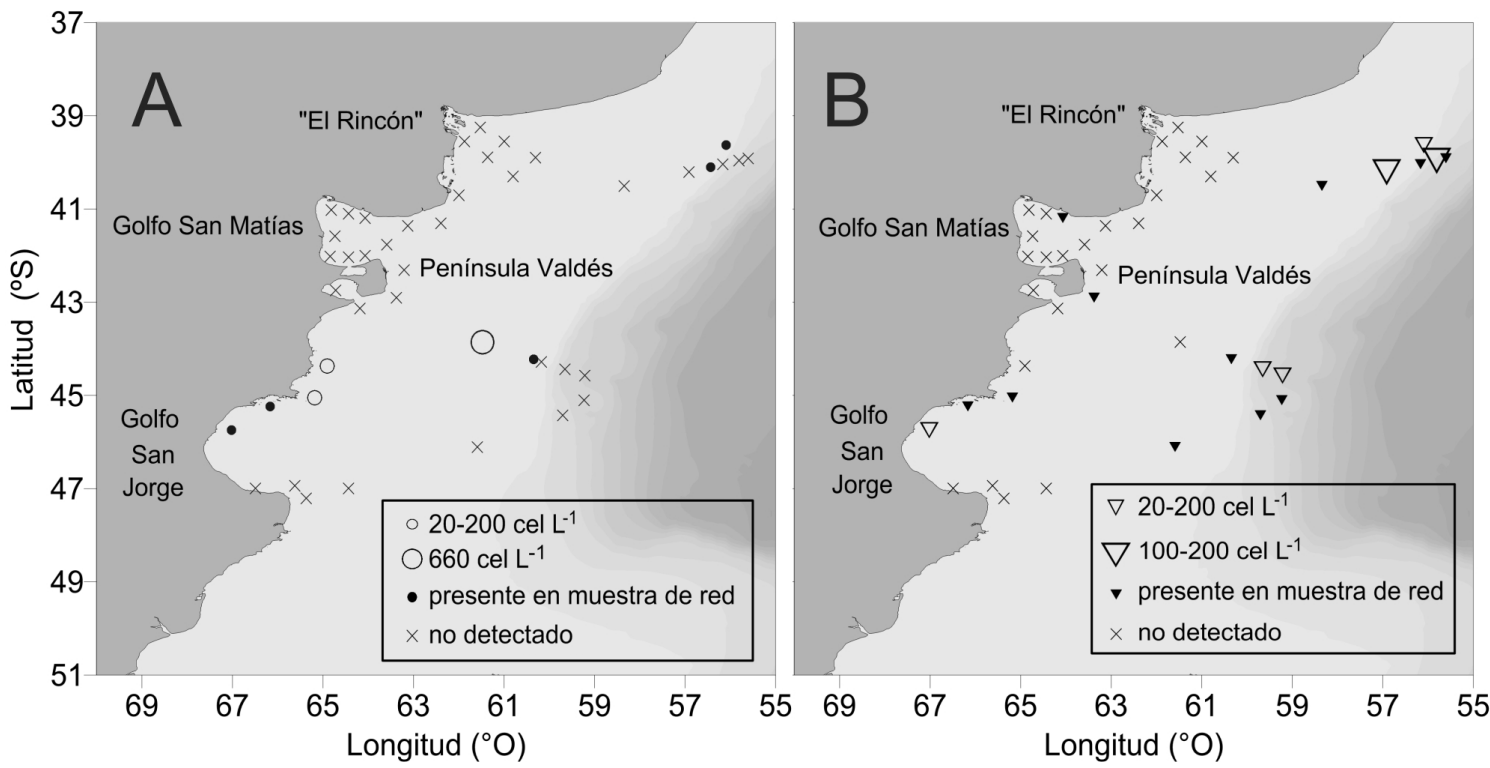

Fig. 7. Distribución y abundancia en muestras cuantitativas y presencia en muestras cualitativas de Protoceratium reticulatum (A) y G. spinifera (B) durante la C3. 

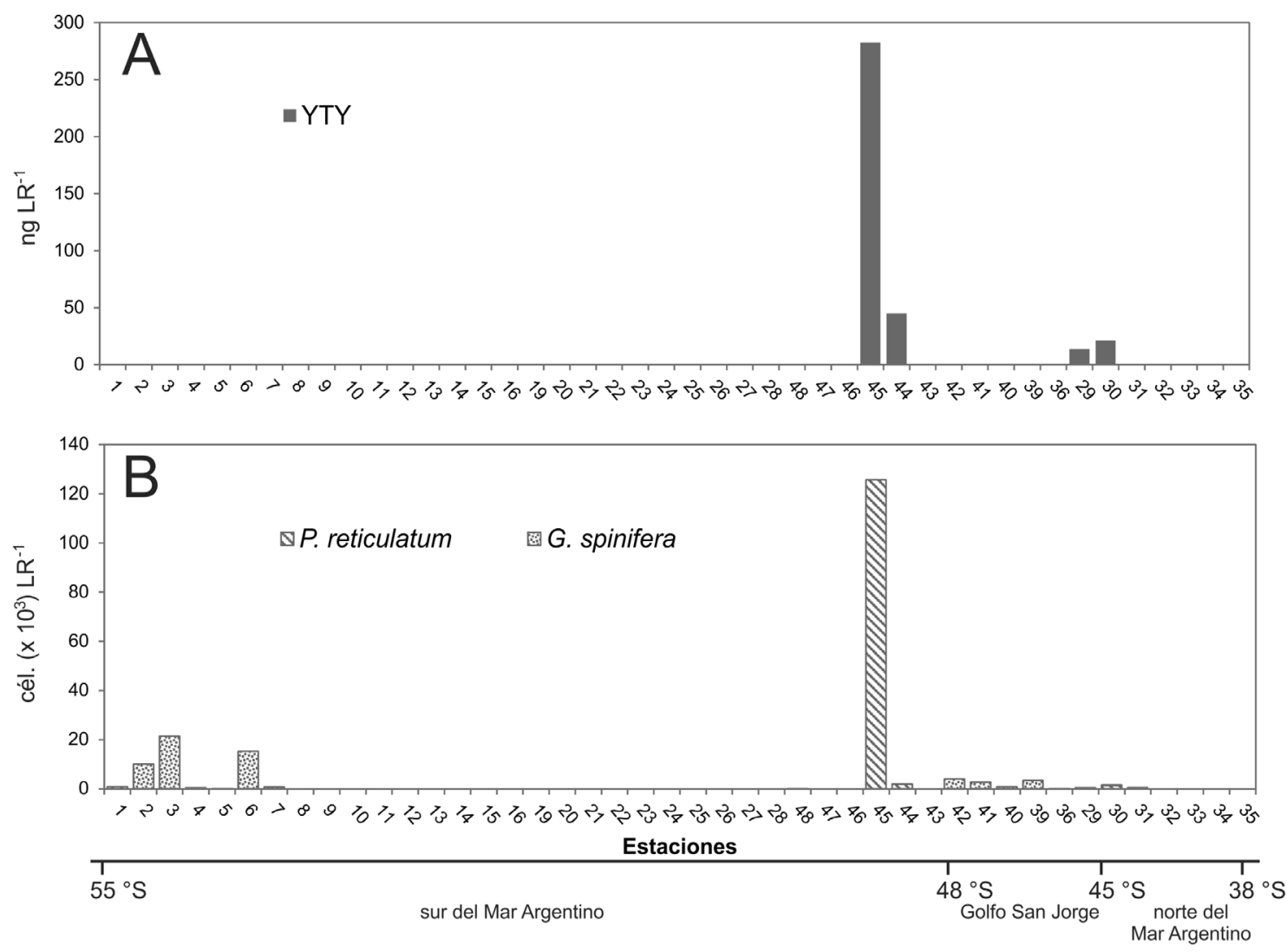

Fig. 8. Concentración de YTX (A) y abundancia de células de P. reticulatum y G. spinifera (B) en la fracción de 20-50 $\mu \mathrm{m}$ de muestras cualitativas a lo largo de la C3.

con las observaciones previas de Akselman et al. (2015) para las poblaciones de Argentina. Por el contrario, las poblaciones naturales de $P$. reticulatum analizadas en un sitio cercano a su localidad tipo (Strib, Dinamarca) presentaron un $50 \%$ de especímenes con una placa intercalar y 3 placas apicales y el otro $50 \%$ sin placa intercalar y con 4 placas apicales (Hansen et al., 1996/1997), con la consecuente variabilidad en el patrón de placas de la especie (3', 1a, 6", 6c, 7s, 6"', 2"'" vs 4', 0a, 6", $6 \mathrm{c}, 7 \mathrm{~s}, 6^{\prime \prime \prime}, 2$ "'"). Asimismo, un cultivo aislado del mismo sitio presentó células con una división de la placa intercalar en tres placas, indicando un grado de variabilidad adicional en la fórmula epitecal de la especie (3', 3a, 6", 6c, 7s, 6"', 2"'") (Hansen et al., 1996/1997), la cual no fue observada en las poblaciones estudiadas en este trabajo.

Los ejemplares del complejo Gonyaulax spinifera analizados en este estudio también presentaron un contorno particular dado por un prominente cuello y dos espinas antapicales, una fuerte reticulación tecal y un marcado desplazamiento y entrecruzamiento cingular semejante al descripto por Balech (1988), aunque alcanzaron dimensiones mayores que las mencionadas en la literatura (Balech, 1988; Gárate-Lizárraga et al., 2014). Los especímenes más pequeños con dos espinas y una reticulación suave se corresponden con la especie $G$. spinifera, mientras que las células con más de dos espinas antapicales, con una reticulación marcada y de mayor tamaño se corresponden con G. digitalis (Balech, 1988; Ellegaard et al., 2003). Dodge (1989), Steidinger \& Tangen (1997), Lewis et al. (1999) y Ellegaard et al. (2003) han mencionado que la identificación microscópica de especies dentro del complejo G. spinifera resulta dificultosa e incierta, y que las diferencias morfológicas entre los quistes parecen representar 


\section{E. Fabro et al. - Dinoflagelados productores de yessotoxinas en el Mar Argentino}

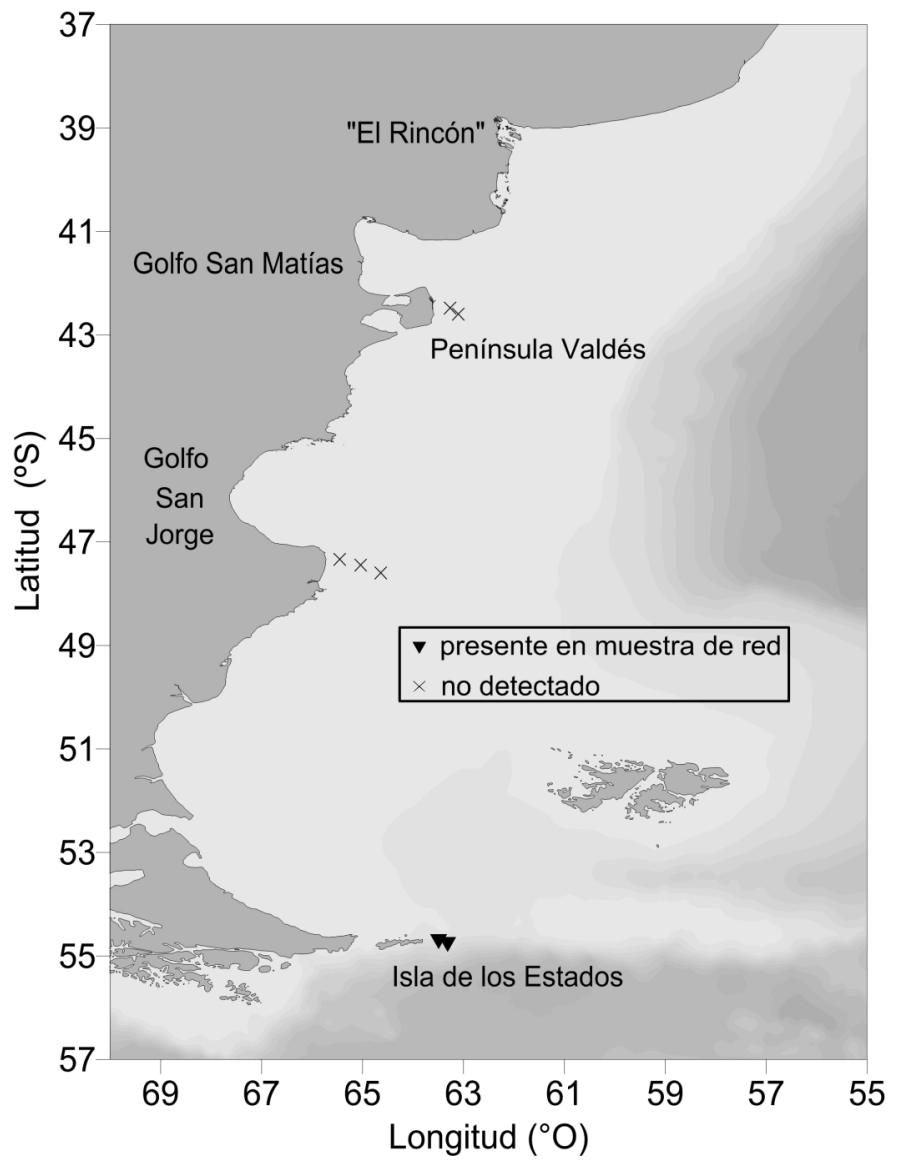

Fig. 9. Distribución del complejo Gonyaulax spinifera en muestras cualitativas durante la C4.

mejor las diferencias genéticas entre las especies que las características morfológicas de las células vegetativas. Por otro lado, la variabilidad molecular del complejo podría implicar la presencia de especies crípticas ya que existen cepas de $G$. spinifera que no forman un grupo monofilético sino que poseen mayor cercanía filogenética con otras especies de morfología similar, como $G$. digitalis (Riccardi et al., 2009). No obstante, las pocas secuencias disponibles para este complejo de especies dificulta la determinación fehaciente a nivel específico desde el punto de vista molecular (Riccardi et al., 2009). En este contexto y dada la incertidumbre que actualmente existe sobre la identidad de las especies del complejo G. spinifera (Riccardi et al., 2009), en este estudio se optó por considerar a los ejemplares definidos en base a su morfología como G. spinifera y G. digitalis como integrantes del complejo de especies G. spinifera.

\section{Distribución y toxinas asociadas}

El patrón de distribución de $P$. reticulatum encontrado en este estudio se asemeja al mencionado en los registros históricos de la especie desde los 37 a los $47^{\circ} \mathrm{S}$ (Balech, 1988), aunque Akselman et al. (2015) la hallaron también más al sur, a los 49 y $53^{\circ} \mathrm{S}$. Por otro lado, el complejo G. spinifera presentó una distribución más amplia, desde los $39^{\circ} \mathrm{S}$ a los $55^{\circ} \mathrm{S}$, lo cual concuerda con la distribución citada en la literatura, desde los $37^{\circ} \mathrm{S}$ hasta la convergencia antártica (Balech, 1988). Asimismo, G. spinifera se observó a rangos de temperatura y salinidad más amplios que $P$. reticulatum $\left(5-16{ }^{\circ} \mathrm{C} ; 32,2-34,0\right.$ y $10-14{ }^{\circ} \mathrm{C} ; 33,1-33,7$ respectivamente). 
Las densidades celulares detectadas durante este estudio para ambos taxones fueron bajas, con máximos durante la campaña de primavera de 660 y 140 cél. $\mathrm{L}^{-1}$ para $P$. reticulatum y el complejo G. spinifera, respectivamente. Mientras que $P$. reticulatum habitualmente presenta bajas abundancias poblacionales (Aasen et al., 2005; Seguel et al., 2005), G. spinifera suele formar floraciones e incluso producir eventos de muerte masiva de biota marina (Margalef, 1956; RiauxGobin \& Lassus, 1989; Praseno et al. 1999; Fukuyo et al., 2003; Riccardi et al., 2009; GárateLizárraga et al., 2014). Aunque ambas especies fueron consideradas de aguas frías por Balech (1988), experimentos realizados con $P$. reticulatum permitieron establecer que la mayor tasa de división celular se produce a los $20^{\circ} \mathrm{C}$ y la mínima a los 10 ${ }^{\circ} \mathrm{C}$ (Houghton et al., 2016). Asimismo se registró una floración de $P$. reticulatum al norte de Chile bajo condiciones de mezcla de masas de agua cálidas $\left(21\right.$ a $25^{\circ} \mathrm{C}$ ) con masas de agua provenientes de un intenso afloramiento (Álvarez et al., 2011).

Amenudo, cuando una misma toxina es sintetizada por más de una especie, resulta complejo identificar en el campo al organismo responsable de dicha toxicidad. Tal es el caso de la producción de YTXs, debido a la reciente confirmación de Lingulodinium polyedra y Gonyaulax spinifera como especies productoras (Paz et al., 2004; Armstrong \& Kudela, 2006; Riccardi et al., 2009). Particularmente en el Mar Argentino existe un único estudio abocado a la determinación de YTXs y especies productoras (Akselman et al., 2015), por lo cual aún no se posee un conocimiento fehaciente sobre los roles respecto de la producción de toxinas de las dos especies toxígenas citadas para la región ( $P$. reticulatum y $G$. spinifera). Sin embargo, los resultados presentados en este trabajo sustentan la asociación entre $P$. reticulatum y YTXs en el Mar Argentino, ya que durante las C1 y C3 la detección de YTX presentó una clara asociación con la presencia de la mencionada especie. Por el contrario, el complejo G. spinifera estuvo presente en muestras de red en abundancias moderadas durante las $\mathrm{C} 2$ y $\mathrm{C} 4$ en las que no se detectaron YTXs. Los únicos dos cultivos de G. spinifera para los cuales se ha comprobado fehacientemente la producción de YTXs a nivel mundial (utilizando LC-MS), mostraron diferentes perfiles tóxicos. Uno presentó bajas cuotas celulares $\left(5,4\right.$ pg cél..$^{-1}$ ) y dominancia de YTX (como en $P$. reticulatum), mientras que el otro presentó cuotas celulares más altas $\left(33,4\right.$ pg cél..$\left.^{-1}\right)$ y dominancia de homo-YTX (Riccardi et al., 2009). No obstante, el análogo homo-YTX típico de G. spinifera no se detectó en el presente estudio durante ninguna de las cuatro campañas de muestreo realizadas y tampoco existen antecedentes de análisis de toxicidad en cultivo para cepas argentinas.

Las cuotas celulares de YTX para $P$. reticulatum variaron entre 2,2 y 12,5 pg YTX cél. $^{-1}$, y resultaron ser similares a las encontradas para las cepas aisladas del Golfo San Jorge, las cuales presentaron cuotas de 9,1 a 10,2 pg YTX cél.- ${ }^{-1}$ (Akselman et al., 2015) y de 3 a 7 pg YTX cél. ${ }^{-1}$ (Houghton et al., 2016). Por el contrario, durante una floración de $P$. reticulatum en Bahía Mejillones, Chile, las cuotas celulares de YTX fueron considerablemente menores $(0,2$ y 0,4 pg cel. $\left.^{-1}\right)$, aunque los autores mencionan una posible subestimación en el contenido de toxina dada por la preservación de las muestras con formaldehído (Álvarez et al., 2011). En cualquier caso, la producción de YTXs, e incluso los perfiles tóxicos, suelen variar dependiendo del origen de las cepas, e incluso las cuotas celulares en cepas de la misma región suelen presentar una gran variación (ej., 2,9-28,6 pg YTX cél. ${ }^{-1}$ para cuatro cepas de España) (Paz et al., 2007).

El perfil de toxinas asociado a $P$. reticulatum en este estudio estuvo representado únicamente por YTX, coincidente con el perfil hallado en Chile y el Golfo San Jorge, (Krock et al., 2009; Álvarez et al., 2011, Akselman et al., 2015), el cual de acuerdo a Paz et al. (2007) parece ser el típico de $P$. reticulatum.

\section{Conclusiones}

Los datos obtenidos a partir de este estudio confirman a la especie $P$. reticulatum como la principal productora de YTXs en el Mar Argentino, mientras que G. spinifera representa un productor potencial en la región que hasta el momento no ha mostrado una asociación clara con la detección de YTX. El área de registro de YTXs en muestras de plancton, hasta el momento acotada al Golfo San Jorge (Akselman et al., 2015), se amplió a áreas de la plataforma externa cercanas al talud continental $\left(44^{\circ} \mathrm{S}\right)$. No obstante, las mayores concentraciones de YTX y $P$. reticulatum se observaron en el Golfo San Jorge, lo cual puede considerarse como un alerta respecto del desarrollo de futuros eventos tóxicos vinculados a esta especie en la zona. 


\section{E. Fabro et al. - Dinoflagelados productores de yessotoxinas en el Mar Argentino}

\section{Agradecimientos}

Los autores agradecen a Wolfgang Drebing (AWI) por la extracción y análisis de las toxinas lipofílicas. Asimismo se agradece a la cordial tripulación del buque oceanográfico Puerto Deseado (CONICET-MINDEF, Argentina) y del Motovelero Bernardo Houssay (Prefectura Naval Argentina). Este trabajo estuvo parcialmente financiado por el centro alemán Helmholtz-Gemeinschaft mediante el programa PACES del Alfred Wegener Institute (AWI) y por el proyecto binacional MINCyTBMBF (AL/11/03-ARG 11/021). Además se contó con el financiamiento de los subsidios PIP 0122 (CONICET) y PICT 0576 (ANPCyT) y por el programa IMCONet (FP7 IRSES, Action No. 319718).

\section{BiobliografíA}

AASEN, J., I. A.SAMDAL, C. O. MILES, E. DAHL, L. R. BRIGGS \& T. AUNE. 2005. Yessotoxins in Norwegian blue mussels (Mytilus edulis): uptake from Protoceratium reticulatum, metabolism and depuration. Toxicon 45: 265-272.

AKSELMAN, R. 1996. Estudios ecológicos en el Golfo de San Jorge y adyacencias (Atlántico sudoccidental). Distribución, abundancia y variación estacional del fitoplancton en relación a factores fisico-químicos y la dinámica hidrográfica. Tesis de Doctorado, Facultad de Ciencias Exactas y Naturales, Universidad de Buenos Aires.

AKSELMAN, R., B. KROCK, T. J. ALPERMANN, U. TILLMANN, M. BOREL, G. O. ALMANDOZ, \& M. E. FERRARIO. 2015. Protoceratium reticulatum (Dinophyceae) in the austral Southwestern Atlantic and the first report on YTX-production in shelf waters of Argentina. Harmful Algae 45: 40-52.

ÁlVAREZ, G., E. URIBE, R. DÍAZ, M. BRAUN, C. MARIÑO \& J. BLANCO. 2011. Bloom of the Yessotoxin producing dinoflagellate Protoceratium reticulatum (Dinophyceae) in Northern Chile. J. Sea Res. 65: 427-434.

ARMSTRONG, M. \& R. KUDELA. 2006. Evaluation of California isolates of Lingulodinium polyedrum for the production of yessotoxin. Afr. J. Mar. Sci. 28: 399-401.

AUNE, T., R. SØRBY, T. YASUMOTO, H. RAMSTAD \& T. LANDSVERK. 2002. Comparison of oral and intraperitoneal toxicity of yessotoxin towards mice. Toxicon 40: 77-82.

BALECH, E. 1988. Los dinoflagelados del Atlántico Sudoccidental. Publ. Espec. Inst. Esp. Oceanogr. 1, Madrid.
DODGE, J. D. 1989. Some revisions of the Family Gonyaulacaceae (Dinophyceae) based on a scanning electron microscope study. Bot. Mar. 32: 275-298.

DRAISCI, R., E. FERRETTI, L. PALLESCHI, C. MARCHIAFAVA, R. POLETTI, A. MILANDRI, A. CEREDI \& M. POMPEI. 1999. High levels of yessotoxin on mussels and presence of yessotoxin and homoyessotoxin in dinoflagellates of the Adriatic Sea. Toxicon 37: 1187-1193.

ELLEGAARD, M., N. DAUGBJERG, A. ROCHON, J. LEWIS \& I. HARDING. 2003. Morphological and LSU rDNA sequence variation within the Gonyaulax spinifera-Spiniferites group (Dinophyceae) and proposal of $G$. elongata comb. nov. and $G$. membranacea comb. nov. Phycologia 42: 151-164.

FRITZ, L. \& R. E. TRIEMER. 1985. A rapid simple technique utilizing Calcofluor white M2R for the visualization of dinoflagellate thecal plates. $J$. Phycol. 21: 662-664.

FUKUYO, Y., Y. SAKO, K. MATSUOKA, I. IMAI, M. TAKAHASI \& M. WATANABE. 2003. Biological character of red-tide organisms. In: OKAICHI, T. (ed.), Red Tides, pp. 61-153. Terra Scientific Publishing Company, Tokyo.

GÁRATE-LIZÁRRAGA, I., M.D.S. MUÑETONGÓMEZ, B. PÉREZ-CRUZ \& J.A. DÍAZ-ORTIZ. 2014. Bloom of Gonyaulax spinifera (Dinophyceae: Gonyaulacales) in Ensenada de La Paz lagoon, Gulf of California. CICIMAR Oceánides 29: 11-18.

GAZZETTA UFFICIALE DELLA REPUBBLICA ITALIANA. 2002. No. 165. Italian Ministry Decree (Decreto Ministeriale) dated May 16, 2002: 16-19.

GRAHAM, L. E. \& L. W. WILCOX. 2000. Algae. Prentice-Hall, Upper Saddle River, New York.

HANSEN, G., O. MOESTRUP \& K. R. ROBERTS. 1996/1997. Light and electron microscopical observations on Protoceratium reticulatum (Dinophyceae). Arch. Protistenk. 147: 381-391.

HOUGHTON, C., M. P. HERNANDO, G. MALANGA, B. KROCK \& U. TILLMANN. 2016. Temperature effects on growth, yessotoxin content, and oxidative stress of Protoceratium reticulatum from Argentina (South Atlantic Ocean). The $17^{\text {th }}$ International Conference on Harmful Algae Abstract book, Florianópolis, Brasil, p. 116.

ICES. 2006. Report on the ICES/IOC workshop on new and classic techniques for the determination of numerical abundance and biovolume of $\mathrm{HAB}$ species - evaluation of the cost, time-efficiency and intercalibration methods (WKNCT), 22-27 August 2005, Kristineberg, Sweden. ICES CM 2005/C: 10.

KONISHI, M., X. YANG, B. LI, C. R. FAIRCHILD \& Y. SHIMIZU. 2004. Highly cytotoxic metabolites from the culture supernatant of the temperate dinoflagellate Protoceratium cf. reticulatum. J. Nat. Prod. 67: 1309-1313. 
KROCK B., U. TILLMANN, U. JOHN \& A. D. CEMBELLA. 2008. LC-MS-MS aboard ship: tandem mass spectrometry in the search for phycotoxins and novel toxigenic plankton from the North Sea. Anal. Bioanal. Chem. 392: 797-803.

KROCK, B., C. G. SEGUEL, K. VALDERRAMA \& U. TILLMANN. 2009. Pectenotoxins and yessotoxin from Arica Bay, North Chile as determined by tandem mass spectrometry. Toxicon 54: 364-367.

LASSUS, P., N. CHOMÉRAT, P. HESS \& E. NÉZAN. 2016. Toxic and harmful microalgae of the World Ocean. IOC Manuals and Guides 68, International Society for the Study of Harmful Algae (ISSHA) / Intergovernmental Oceanographic Commission of UNESCO (IOC), Copenhagen.

LEGRESLEY, M. \& G. MCDERMOTT. 2010. Counting chamber methods for quantitative phytoplankton analysis-haemocytometer, Palmer-Maloney cell and Sedgewick-Rafter cell. In: KARLSON, B., C. CUSACK \& E. BRESNAN (eds.), Microscopic and molecular methods for quantitative phytoplankton analysis, pp. 25-30. IOC Manual and Guides 55, Intergovernmental Oceanographic Commission of UNESCO, Paris.

LEWIS, J., A. ROCHON \& I. HARDING. 1999. Preliminary observations of cyst-theca relationships in Spiniferites ramosus and Spiniferites membranaceus (Dinophyceae). Grana 38: 113-124.

MACKENZIE, L., P. TRUMAN, M. SATAKE, T. YASUMOTO, J. ADAMSON, D. MOUNTFORT \& D. WHITE. 1998. Dinoflagellate blooms and associated DSP toxicity in shellfish in New Zealand. In: REGUERA, B., J. BLANCO, M. L. FERNÁNDEZ \& T. WYATT (eds.), Harmful Microalgae, pp. 74-77. Xunta de Galicia and IOC of UNESCO, Santiago de Compostela.

MARGALEF, R. 1956. Estructura y dinámica de la "purga de mar" en la Ría de Vigo. Investigación Pesquera 5: 113-134.

MILES, C. O., I. A. SAMDAL, J. A. B. AASEN, D. J. JENSEN, M. A. QUILLIAM, D. PETERSEN, L. M. BRIGGS, A. L. WILKINS, F. RISE, J. M. COONEY \& A. L. MACKENZIE. 2005. Evidence for numerous analogs of yessotoxin in Protoceratium reticulatum. Harmful Algae 4: 1075-1091.

MUNDAY, R., T. AUNE \& G. P. ROSSINI. 2008. Toxicology of the yessotoxins. In: BOTANA, L. M. (ed.), Seafood and Freshwater Toxins: Pharmacology, Physiology and Detection, second ed., pp. 329-339. CRC Press, Taylor \& Francis Group, Boca Raton.

PAZ, B., P. RIOBÓ, M. L. FERNÁNDEZ, S. FRAGA \& J. M. FRANCO. 2004. Production and release of yessotoxins by the dinoflagellates Protoceratium reticulatum and Lingulodinium polyedrum in culture. Toxicon 44: 251-258.
PAZ, B., P. RIOBÓ, I. RAMILO \& J. M. FRANCO. 2007. Yessotoxins profile in strains of Protoceratium reticulatum from Spain and USA. Toxicon 50: 1-17.

PAZ, B., J. BLANCO \& J. M. FRANCO. 2013. Yessotoxins production during the culture of Protoceratium reticulatum strains isolated from Galician Rias Baixas (NW Spain). Harmful Algae 21-22: 13-19.

PRASENO, D. P., Y. FUKUYO, R. WIDIARTI, Y. E. BADRUDIN \& S. S. PAIN, 1999. The HAB/red tide blooms in Indonesian waters 1997/1998. In: Proceedings of the Fourth ASEAN-Canada Technical Conference on Marine Sciences, pp. 432-437. Malaysia.

RHODES, L. L., P. MCNABB, M. DE SALAS, L. BRIGGS, V. BEUZENBERG \& M. GLADSTONE. 2006. Yessotoxin production by Gonyaulax spinifera. Harmful Algae 5: 148-155.

RIAUX-GOBIN, C. \& P. LASSUS. 1989. Conditions hydroclimatiques d'une eau colorée à Gonyaulax spinifera (dinoflagellé) dans une ria du Nord-Finistère. Bot. Mar. 32: 491-498.

RICCARDI, M., F. GUERRINI, F. RONCARATI, A. MILANDRI, M. CANGINI, S. PIGOZZI, E., RICCARDI, A. CEREDI, P. CIMINIELLO, C. DELL'AVERSANO, E. FATTORUSSO, M., FORINO, L. TARTAGLIONE \& R. PISTOCCHI. 2009. Gonyaulax spinifera from the Adriatic Sea: toxin production and phylogenetic analysis. Harmful Algae 8: 279-290.

SATAKE, M., L. MACKENZIE \& T. YASUMOTO. 1997. Identification of Protoceratium reticulatum as the biogenic origin of yessotoxin. Nat. Toxicol. 5: 164-167.

SEGUEL, M., M. A., TOCORNAL \& A. SFEIR. 2005. Floraciones algales nocivas en los canales y fiordos del sur de Chile. Cienc. Tecnol. Mar. 28: 5-13.

STEIDINGER, K. \& K. TANGEN. 1997. Dinoflagellates. In: TOMAS, C. R. (ed.), Identifying Marine Phytoplankton, pp. 387-584. Academic Press, San Diego.

TERAO, K., E. ITO, M. OARADA, M. MURATA \& T. YASUMOTO. 1990. Histopathological studies on experimental marine toxin poisoning-5. The effects on mice of yessotoxin isolated from Patinopecten yessoensis and of a desulfated derivative. Toxicon 28 : 1095-1104.

TUBARO, A., L. SIDARI, R. DELLA-LOGGIA \& T. YASUMOTO. 1998. Occurrence of yessotoxin-like toxins in phytoplankton and mussels from Northern Adriatic Sea. In: REGUERA, B., J. BLANCO, M .L. FERNÁNDEZ, \& T. WYATT (eds.). Harmful Algae, pp. 470-472. Xunta de Galicia and Intergovernmental Oceanographic Commission of UNESCO, Paris.

UTERMÖHL, H. 1958. Zur Vervollkommnung der quantitativen Phytoplankton Methodik. Mitt. Int. Ver. Theor. Angew. Limnol. 9: 1-38.

Recibido el 13 de agosto de 2018, aceptado el 26 de octubre de 2018. Editora: Eugenia Alicia Sar. 